\title{
Extraction and Determination of Amygdaline in Iraqi Plant Seeds Using the Combined Simple Extraction Procedure and High-Performance Liquid Chromatography
}

\author{
Suad S. Muhammad $\quad$ Sumayah M. Abbas** \\ Zuhair A-A khammas* \\ Received 11, March, 2012 \\ Accepted 15, July, 2012
}

\begin{abstract}
:
In this study, amygdaline in Iraqi plant seeds was extracted and isolated from their seeds matrix using reflux procedure and subsequently identified and determined by high performance liquid chromatography (HPLC) on reversed phase column of LC-18 $(150 \mathrm{~mm} \times 4.6 \mathrm{~mm}, 5 \mu \mathrm{m})$ with actonitrile :water $(50: 50)$ as mobile phase at flow rate of $(0.5 \mathrm{~mL} / \mathrm{min})$ and detection at wavelength of $215 \mathrm{~nm}$. The experimental results indicated that the linearity of calibration is in the range of 1.0$30.0 \mathrm{mg} \mathrm{L}^{-1}$ amygdaline with the correlation coefficient of 0.9949 . The limit of detection (LOD) and limit of quantitation (LOQ) for amygdaline were of 0.88 and $2.93 \mathrm{mg} \mathrm{L}^{-1}$ in standard pure sample. The mean recovery percent is $97.34 \pm 0.58$ at $95 \%$ confidence interval and relative standard deviation in the range of 1.19-2.08 \%. The content of amygdaline in plant samples was $4.60 \pm 0.47 \mathrm{~g} / 100 \mathrm{~g}$, and $0.27 \pm 0.029$ $\mathrm{g} / 100 \mathrm{~g}$ of apricot and citrullus colocynth respectively.
\end{abstract}

Keywords: Amygdaline, Iraqi plants, soxhlet method, FTIR, HPLC

\section{Introduction:}

In fact, the apricot is not merely consumed as a fresh or dried fruits by humans but its kernel in sweet form also consumed as dried fruits, whereas its bitter kernel can be used as a raw material in the cosmetic and pharmaceutical industries. In addition, cooking oil, benzaldehyde, activated carbon, amygdaline and hydrocyanic acid can be produced from the apricot seeds [1-2 ]. The seeds of these fruits have also high protein content and can be used as a food or feed ingredient; however, they contain approximately $50 \mathrm{nmol} / \mathrm{mg}$ of plant tissue of the potentially toxic cyanogenic glycosides amygdaline and prunasin depending on the plant species and environment [3].
Amygdaline is deemed as a main component of apricot seed extract and a natural cyanogenetic glycoside compound found in the greatest concentration in the seeds of the rosaceous fruits family, such as the $\operatorname{apricot}(\mathrm{P}$. armeniaca) pits and other bitter nuts as bitter almonds( $\mathrm{P}$. amygdalus var. amara ) [4]. It is a reducing disaccharide consisting of two molecules of $\beta$-glucose linked by $\beta-1,6$ linkage, chemically named as [(6-O- $\beta$-d-Glucopyranosyl- $\beta$-dglucopyranosyl) oxy] benzeneacetonitrile and its chemical structure is shown in Fig.1

\footnotetext{
*Department of Chemistry, College of Science for women, University of Baghdad,

*** Department of Chemistry, College of Ibn- Alhaytham, University of Baghdad, Aadhamiya, Baghdad, Iraq
} 
$\mathrm{C}_{20} \mathrm{H}_{27} \mathrm{NO}_{11}=457.4$

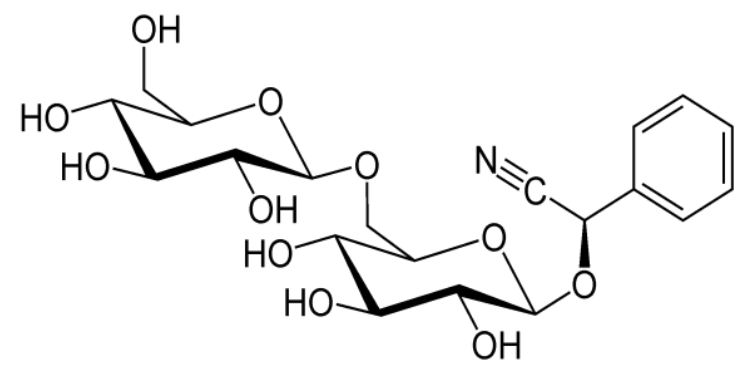

Fig. 1 Chemical structure of amygdaline (CAS - 29883-15-6)

Amygdaline is also referred to as laetrile and vitamin $\mathrm{B}_{17}$ and was first publicized in the early 1980 s by the National Cancer Institute (NCI) as a 'natural' non-toxic cure for cancer, but found no evidence to support the use of laetrile in cancer treatment [5]. Consequently, laetrile (a purified form of amygdaline) produced by Cyto Pharma of Mexico was banned from use in cancer therapy by the Food and Drug Administration (FDA) and the European Union because the results did not suggest laetrile to be effective product [1, 6-8]. Although a small number of reports suggested that laetrile may have some slight anticancer activity, UK legislation drawn up in 1984, restricts the availability of cyanogenetic substances so that amygdaline can only be administered under medical supervision [9]. Scientific research is still continuing to support the claims made for amygdaline (laetrile) as an alternative cancer treatment or its anticancer effect.

Nevertheless, there are some studies reported that amygdaline may be hazardous for human health [10-11] due to enzymatic hydrolysis following its oral ingestion results in the release of hydrogen cyanide $(\mathrm{HCN})$, which is rapidly absorbed from the upper gastrointestinal tract and which can lead to respiratory failure. It has been estimated that oral doses of $50 \mathrm{mg}$ of $\mathrm{HCN}$ can be fatal, equivalent to about 50-60 apricot kernels [12].Accordingly
, the establishment of an accurate and precise analytical method for the separation and determination of amygdaline in the fruit seeds is a must. The chemical literatures revealed that a few analytical methods for the extraction and determination of amygdaline in pure form and natural products have been reported, including UV-spectrophotometry electrochemical sensor [14] gas chromatography [15] capillary electrophoresis [16] enzymatic method [17] High-performance thin layer chromatography [18] and Highperformance liquid chromatography [19-25]. Although these methods have provided a satisfactory analytical figures of merit for the determination of amygdaline in different plant matrices, but some were failed in the sample pretreatment characterized by long separation time and low separation efficiency and gave unobvious identification of amygdaline in the resulting extract.

In this work, amygdaline is extracted from Iraqi fruits kernels (ie. Apricot sweet ,bitter kernels and citrullus colocynth) by simple soxhelt procedure using isopropanol as extracting solvent following by chemical and IR identification of amygdaline which then determined quantitatively by high-performance liquid chromatography . 


\section{Materials and Methods: Apparatus:}

The chromatographic system consists of a high-performance liquid chromatography HPLC type (Shimadzu, Japan) equipped with UVVis detector model SPD-10A(C)vp, column thermostat type CTO10A(C0vp , Degasser(DG-1310), injection valve containing $20-\mu \mathrm{L}$ and $50-\mu \mathrm{L}$ sample loop. The system is equipped with a commercial column type LC-18 $(150 \mathrm{~mm} \times 4.6 \mathrm{~mm}, 5 \mu \mathrm{m})$ model Shim-pack VP-ODS .The whole system is controlled by using a computer working with software. The mobile phase used is acetonitrile: water 50: $50(\mathrm{v} / \mathrm{v})$, at flow rate of 0.5 $\mathrm{mL} / \mathrm{min}$. The detection is made at wave length of $215 \mathrm{~nm}$. The injector is washed with the mobile phase between successive injections and also after experiment.

\section{Reagents and Solutions}

A pharmaceutical grade of amygdaline (purity > 99.6\%) is supplied sigma-Aldrich (USA) and HPLC-grade acetonitrile (Merck, Darmstadt, Germany) is used. Isopropanol, ethyl ether, sodium hydroxide, ferrous sulphate, hydrochloric acid and ferric chloride are purchased from $\mathrm{BDH}$ and used without purification. A stock solution of amygdaline $\left(1000 \mathrm{mg} \mathrm{L}^{-1}\right)$ is prepared by dissolving $1 \mathrm{~g}$ of pure material in one liter distilled water and kept in refrigerator before use. Working standard solutions are then prepared by a suitable dilution of the stock solution with DW.

\section{Sampling and Extraction Procedure}

Iraqi apricot fruits (sweet and bitter seeds) and citrullus colocynth are purchased from local markets and after sampling the fruits, the seeds are pulled out, and then dried at room temperature for 6 days to achieve standard drying and subsequently kept in electrical oven at $30{ }^{\circ} \mathrm{C}$ for $24 \mathrm{~h}$.
After the outer shells of the apricot kernel and citrullus colocynth have been cracked out, the extracted seeds dried previously are pulverized by means of a blender. $5 \mathrm{~g}$ of each sample is extracted three times with $100 \mathrm{~mL}$ iso-propanol using soxhlet technique for $2 \frac{1 / 2}{h}$ at $90{ }^{\circ} \mathrm{C}$. The contents are passed through a filter paper (Wattmann 42), and then the extract is set aside for $72 \mathrm{~h}$ until amygdaline precipitate settle down. The product is washed out three times with ethylic ether to obtain a dry powder of amygdaline.

\section{Identification of Amygdaline in Extracted Sample}

Prussian blue test: one gram of amygdaline from the extracted sample is extracted by shaking with $20 \mathrm{~mL}$ water for $1 \mathrm{~h}$, filtered and $1 \mathrm{~mL}$ of the filtrate is used for the cyanide group according to the procedure outlined elsewhere [26] .The filtrate solution containing (-CN group) is rendered strongly alkaline with sodium hydroxide solution, then a few milliliters of a freshly prepared saturated of ferrous sulphate added and the mixture boiled. R-ferrocyanide is thus formed. To neutralize any free alkali, the contents are acidified with hydrochloric acid to obtain a clear solution which give a precipitate of Prussian blue upon the addition of a little ferric chloride solution.

FTIR Method:

The dried solid samples are pressed into pellets (with $\mathrm{KBr}$ ) and the spectrum of amygdaline in pure form and samples is scanned using Shimadzu FTIR-8201A (Japan) single beam laser Infrared Spectrometer.

\section{Quantitative Analysis of Amygdaline in Sample}

Under the optimized conditions, a series of working solutions of amygdaline are injected via the injection valve of the HPLC instrument to construct a calibration graph. This is 
done by comparing their peak areas with the concentration standard solutions of Amygdaline from which the amount of amygdaline in each of the selected sample are determined by linear regression. The optimized conditions are summarized in Table 1.

Table 1 Optimized chromatographic conditions for the separation and determination of amygdaline.

\begin{tabular}{|c|c|}
\hline Parameter & Condition \\
\hline Column type & LC-18 (150mm x 4.6mm, $5 \mu \mathrm{m})$ \\
\hline Mobile Phase & acetonitrile: water 50: $50(\mathrm{v} / \mathrm{v})$ \\
\hline Flow rate & $0.5 \mathrm{~mL} \mathrm{~min}^{-1}$ \\
\hline UV Detection & $215 \mathrm{~nm}$ \\
\hline Injection volume & $20 \mu \mathrm{L}$ \\
\hline Column temperature & $25^{\circ} \mathrm{C}$ \\
\hline
\end{tabular}

\section{Statistical Analysis}

All statistical calculations, such as basic statistics, significance tests, regression equations and correlation coefficients for the calibration curves, were implemented using Minitab version 14 (Minitab Inc., State College, PA, USA) and Excel 2007(Microsoft Office $^{\circledR}$ ).

\section{Results and Discussion: Identification of Amygdaline}

Two methods are used to identify the extracted amygdaline in the sample. First, by using Prussian test to recognize the presence of nitrile group $(-\mathrm{CN})$. The result of the test reveals that a Prussian blue precipitate $\left[\mathrm{Fe}_{4}(\mathrm{CN})_{6}\right]_{3}$ is finally obtained upon addition of a little of ferric chloride solution indicating the presence of nitrile group which reflect that the isolated compound from the selected sample is as cyanogenic glycosides type Amygdaline according to the following reactions[26];

$$
\begin{gathered}
6 \mathrm{CN}^{-}+\mathrm{Fe}^{2+} \\
3\left[\mathrm{Fe}(\mathrm{CN})_{6}\right]^{4-}+4 \mathrm{Fe}^{3+} \longrightarrow\left[\mathrm{Fe}(\mathrm{CN})_{6}\right]^{4-} \\
\longrightarrow\left[\mathrm{Fe}_{4}(\mathrm{CN})_{6}\right]
\end{gathered}
$$

Second, FTIR technique is used to identify amygdaline compound in the selected samples and compared with the standard pure amygdaline. The IR spectra of pure

Amygdaline in pure form, extracted from apricot bitter kernel and citrullus colocynth are shown in Fig. 2,3,4 .It is appeared that IR spectra for two extracts are relatively consistent with the spectrum of pure amygdaline. 


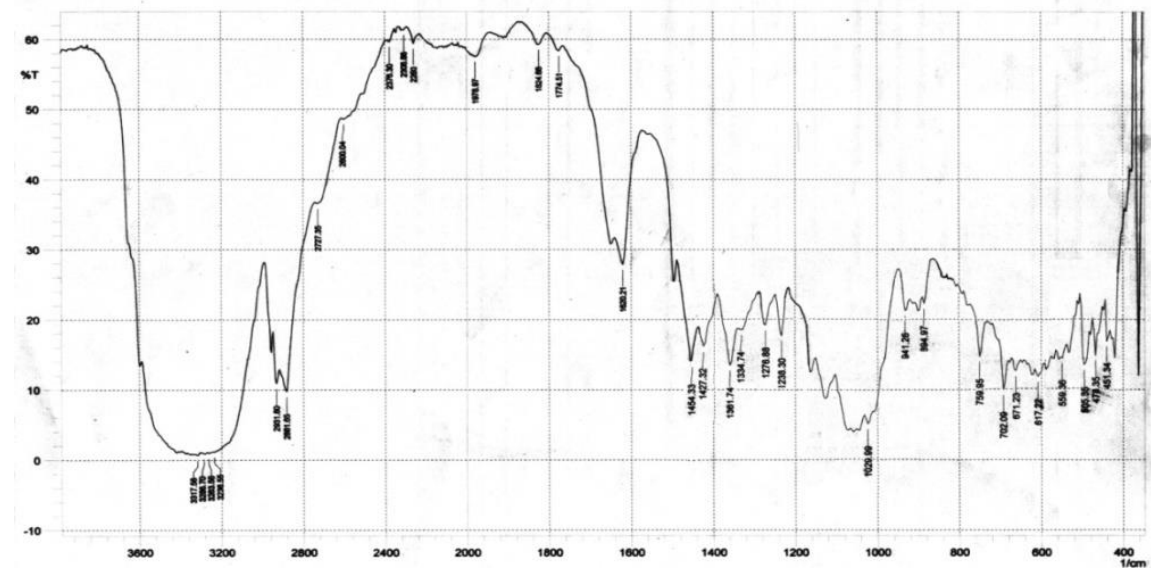

Fig. 2 FTIR spectrum of standard pure amygdaline.

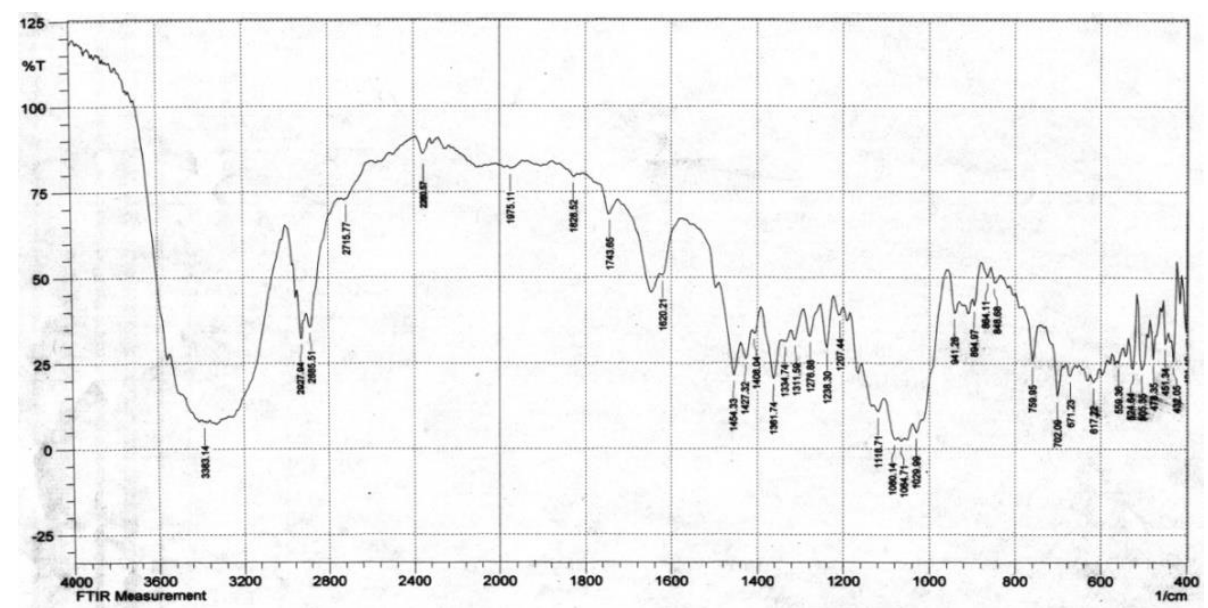

Fig. 3 FTIR spectrum of amygdaline extracted from apricot bitter kernel

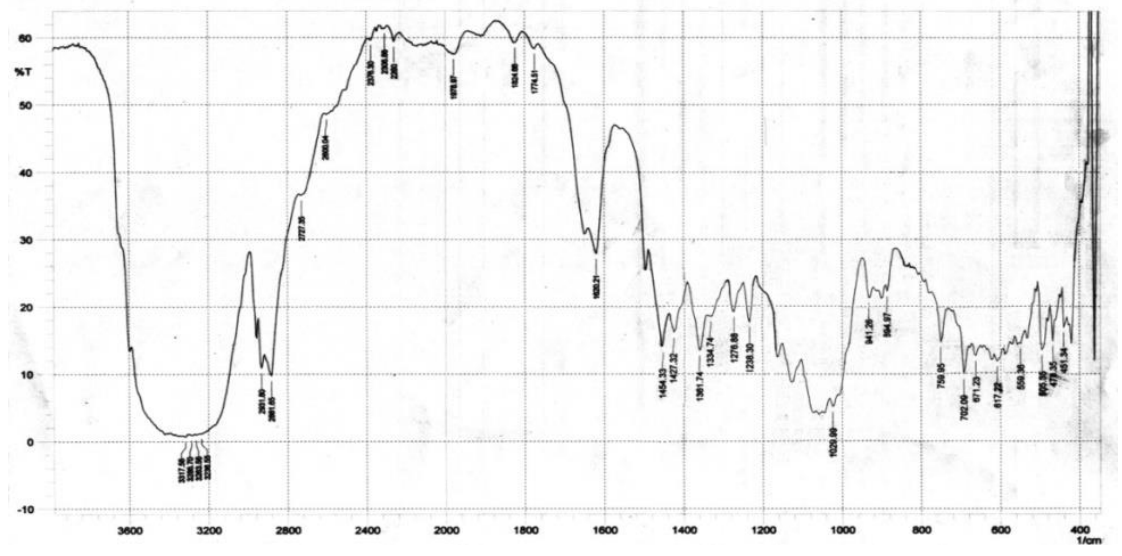

Fig. 4 FTIR spectrum of amygdaline extracted from citrullus colocynth kernel 
The broad peak between 3150 and $3600 \mathrm{~cm}^{-1}$ indicates the stretching vibration of $(\mathrm{O}-\mathrm{H})$ alcoholic group in amygdaline structure. Because of the small changes in dipole moment of the nitrile group $(-\mathrm{C} \equiv \mathrm{N})$, this group gives rise to relatively low intensity bands above $2200 \mathrm{~cm}^{-1}$ in all spectra. The aromatic $\mathrm{C}=\mathrm{C}$ bending appears at $1620.1 \mathrm{~cm}^{-1}$ while aromatic $\mathrm{C}-\mathrm{H}$ bending at $864.11 \mathrm{~cm}^{-1}$. The vibrational bands at $\sim 2885 \mathrm{~cm}^{-1}$ may be due to aliphatic C-H stretching vibrations and that at $2927.9 \mathrm{~cm}^{-1}$ may be due to $\mathrm{C}-\mathrm{H}$ stretching vibrations of the aromatic ring of the amygdaline.

\section{HPLC study}

\section{Chromatographic Characterization}

HPLC is first used as a tool for verification the efficiency of the amygdaline separation in an appropriate purity from the extracted samples via the comparison the retention time of the standard with those extracted from the selected samples under conditions that specified in Table 1. A symmetric chromatographic peak is obtained for standard amygdaline eluted at $6.67 \mathrm{~min}$ (Fig 5).

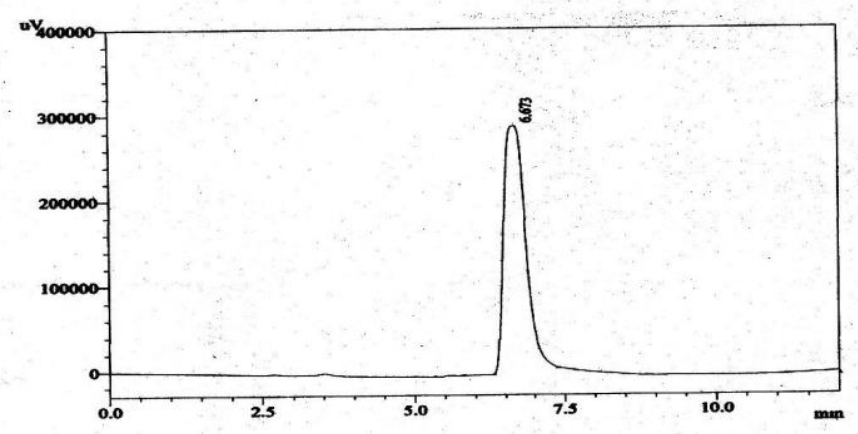

Fig.5 chromatogram of the standard amygdaline

both types of kernels with the presence

The chromatographic profile for amygdaline in the apricot bitter kernel and citrullus colocynth kernel are shown in Fig. 6 and 7. It is observed that a little deviation occurred in retention times (6.58 and $6.57 \mathrm{~min}$ ) for of small shoulder at $7.27 \mathrm{~min}$. This may be ascribed to the presence of other components in the extracted sample matrix indicating that amygdaline is not extracted well.

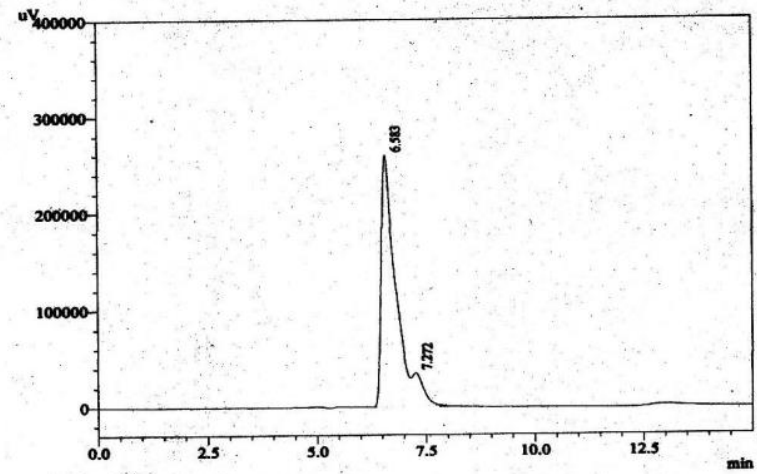

Fig. 6 chromatogram of amygdaline in the extracted apricot bitter kernel 


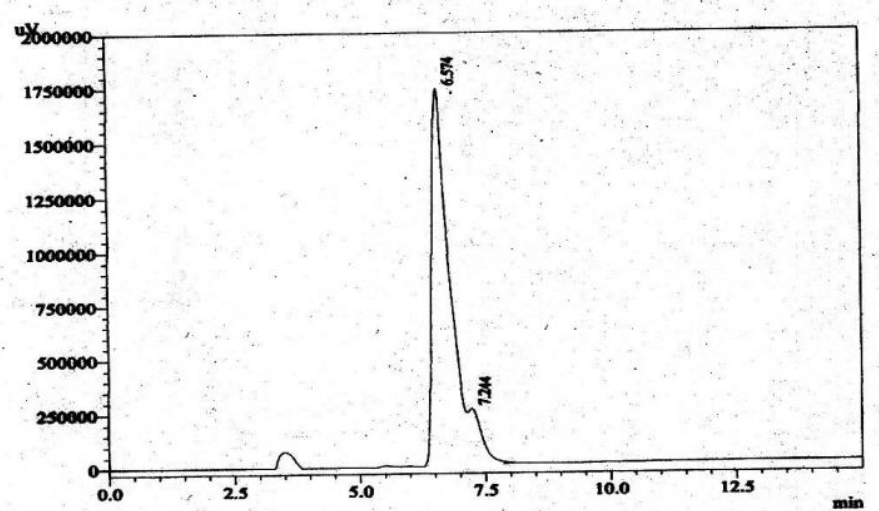

Fig.7 chromatogram of amygdaline in the extracted citrullus colocynth kernel

Whereas no chromatographic peak at $6.6 \mathrm{~min}$ but major peak at $10.58 \mathrm{~min}$ is observed with the sample extracted from apricot sweet kernel (Fig. not shown) indicating no amygdaline exist in this type of sample This may be attributed to the complete degradation of amygdaline in sweet kernel into other components during the extraction process or the presence of small quantity which cannot be detected by the proposed method.

\section{Calibration Curve}

Under

the

optimized chromatographic conditions (Table 1) for the determination of amygdaline, linear calibration graph is established by plotting the peak area versus the amount of amygdaline. Fig. 8 represents the calibration curve and the analytical figures of merit are summarized in Table 2.

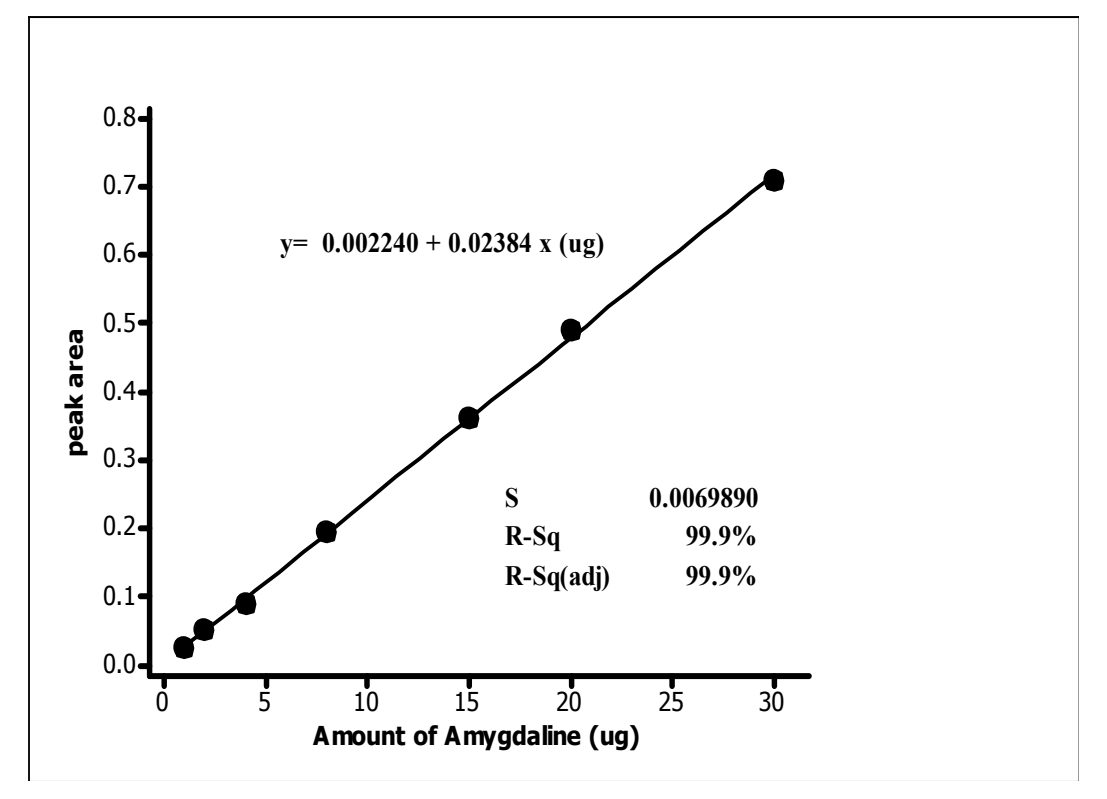

\section{Conc. of amygdaline $\left(\mathrm{mg} \mathrm{L}^{-1}\right)$}

Fig. 8 calibration curve for amygdaline by HPLC 
Linear relationship is obtained between peak areas and the amount of the amygdaline and found to be in the range $1.0-30.0 \mathrm{mg} \mathrm{L}^{-1}$. The statistical evaluation for the calibration graph has shown that a strong correlation between peak area and amygdaline amounts may exist $\left(\mathrm{R}^{2}=99.9 \%\right)$. On the other hand, the analysis of variance (ANOVA) was also prove the linear regression $[\mathrm{y}=(0.002240 \pm 0.0401)$

equation $+(0.02384 \pm 0.00026) \mathrm{x})]$ was statistically valid. This is because of the ratio $\left(\mathrm{MS}_{\mathrm{reg}} / \mathrm{MS}_{\text {error }}\right)$ for 1 and $5 \mathrm{DF}$ is larger than the critical value $\left(\mathrm{F}_{1,5}=5.79\right.$ at $\left.95 \% \mathrm{CI}\right)$, indicating that the predication based on the regression line is satisfactory (Table 3) .

Table 2 Analytical statistics data for the determination of amygdaline.

\begin{tabular}{lc}
\hline parameter & \\
\hline Range of concentration $\left(\mathrm{mg} \mathrm{L}^{-1}\right)$ & $1.0-30.0$ \\
$\mathrm{LOD}\left(\mathrm{mg} \mathrm{L}^{-1}\right)$ & 0.88 \\
$\mathrm{LOQ}\left(\mathrm{mg} \mathrm{L}^{-1}\right)$ & 2.93 \\
Régression line & $\mathrm{y}=0.002240+0.02384 \mathrm{x}$ \\
Correlation coefficient $(\mathrm{r})$ & 0.9949 \\
Coefficient of determination $\left(\mathrm{R}^{2}\right)$ & $99.9 \%$ \\
C.L. for the slope $\left(\mathrm{b} \pm \mathrm{ts}_{\mathrm{b}}\right)$ at $95 \%$ & $0.02384 \pm 0.00026$ \\
C.L. for the intercept $\left(\mathrm{a} \pm \mathrm{ts}_{\mathrm{a}}\right)$ at $95 \%$ & $0.002240 \pm 0.0401$ \\
\hline
\end{tabular}

Normal probability plot of the Residuals, histogram of the residuals, and residuals versus amygdaline are also established (Fig. 9) indicating these plots reveal that the residuals are not normally distributed and that the calibration data points do not contain an

outlier

Table 3: Analysis of Variance of regression line

\begin{tabular}{lrccll}
\hline Source & DF & SS & MS & F & P \\
\hline Regression & 1 & 0.395455 & 0.395455 & 8095.90 & 0.00 \\
Error & 5 & 0.000244 & 0.000049 & & \\
Total & 6 & 0.395699 & & &
\end{tabular}

$\mathrm{DF}=$ degrees of freedom, $\mathrm{SS}=$ sum of squares, $\mathrm{MS}=$ mean of squares, $\mathrm{F}=$ fisher F-test, $\mathrm{P}=$ probability

Limit of detection and limit of quantitation is found to be $0.88 \mathrm{mg} \mathrm{L}^{-}$ ${ }^{1}$ and $2.93 \mathrm{mg} \mathrm{L}^{-1}$ which are much better than that obtained by other workers [23] but is less than that obtained by
Zhao et al [27] who used HPLC with Column Switching Coupled to APCIMS for pharmacokinetic study of amygdaline in rabbit plasma. 

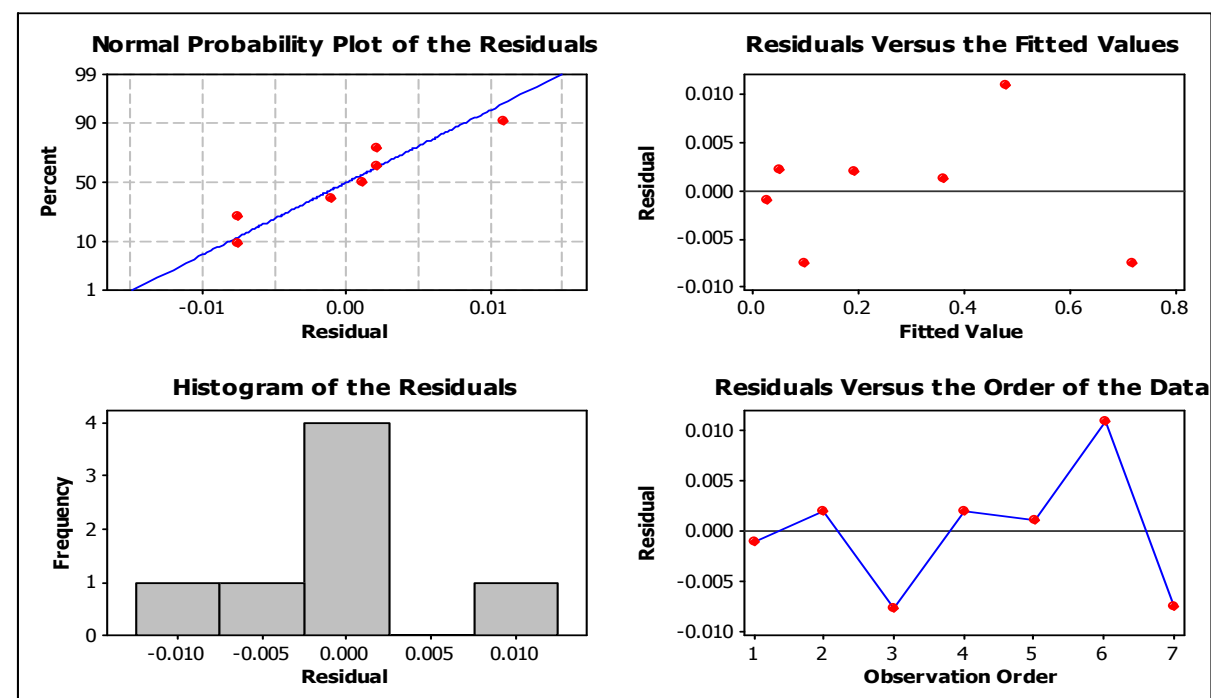

Fig. 9 statistical analysis for calibration curve showing residuals versus the amount of amygdaline

Determination of Amygdaline in the Samples

HPLC method is used for the assay of amygdaline in the extracted kernel samples. The extracted sample solution is diluted such that final concentration of the amygdaline within the limits of linearity of the constructed calibration graph, from which the amount of amygdaline is calculated using the specified regression line (Table 2). The amount of amygdaline in Iraqi apricot bitter kernel is found to be $4.6 \pm 0.47 \mathrm{~g} / 100 \mathrm{~g}$, but no detectable amount is found in sweet apricot kernel. This finding is in harmony with results obtained by Femenia et al [28] which is very high $(5.5 \mathrm{~g} / 100 \mathrm{~g})$ in bitter apricot kernel and is not detected in sweet counterpart. Our results are also in a good agreement with that obtained by Turkish workers [29] whom found the amount of amygdaline in Turkish apricot bitter kernel is between 4.41 and $6.35 \mathrm{~g} / 100 \mathrm{~g}$ but low amounts are detected in range of $0.60-1.56 \mathrm{~g} / 100 \mathrm{~g}$ in sweet variety.
The amount of amygdaline in Iraqi citrullus colocynth kernel is found to be $0.27 \pm 0.029 \mathrm{~g} / 100 \mathrm{~g}$. The accuracy of HPLC method is determined by spiking known amounts of amygdaline in the apricot kernel extract sample and diluted such that final amount of the analyte within the limits of linearity of the constructed calibration graph. The results are summarized in Table 4. For precision, five replicate analysis of each spiked sample are made and the average found to be $1.59 \pm 0.63 \%$ (Table 4 ). 
Table 4 Accuracy and precision of HPLC method

\begin{tabular}{|c|c|c|c|c|c|}
\hline $\begin{array}{c}\text { Amount } \\
\text { taken } \\
\left(\mathrm{mg} \mathrm{L}^{-1}\right)\end{array}$ & $\begin{array}{c}\text { Amount } \\
\text { found } \\
\left(\mathrm{mg} \mathrm{L}^{-1}\right)\end{array}$ & $\begin{array}{c}\text { Rec } \\
(\%)\end{array}$ & $\begin{array}{c}\mathrm{E}_{\text {rel }} \\
(\%)\end{array}$ & Rec\% $\pm \mathrm{s} \mathrm{t} / \sqrt{ } *$ & $\begin{array}{c}\text { RSD\% } \\
(\mathrm{n}=5)\end{array}$ \\
\hline 5 & 4.85 & 97.0 & -3 & $97.34 \pm 0.58$ & 2.08 \\
10 & 9.78 & 97.8 & -2.2 & & 1.52 \\
15 & 14.62 & 97.3 & -2.5 & & 1.19 \\
\hline
\end{tabular}

$*$ at $95 \%$ confidence interval $\left(\mathrm{t}_{\text {crit }}=4.30\right.$ for 2 degree of freedom)

\section{Conclusions :}

A simple extraction and HPLC method for identifying and quantifying of amygdaline in Iraqi plant seeds have been established with uncomplicated optimization procedure. The analytical figures of merit such as linearity, detection limit, accuracy, and precision obtained by HPLC technique as validation method proved that it is reproducible and selective for the analysis of amygdaline in plant seeds. Among the types of seeds studied, bitter kernel had higher amygdaline content than the sweet one and citrullus colocynth kernel. In this investigation, amygdaline content in Iraqi apricot bitter kernel is superb and deserved further studies for the purpose of pharmaceutical evaluation. Whereas, in sweet kernel there is no amygdaline detected.

\section{References:}

1. Asma B.M. and Misirli A. 2007." Kay1s1 cekirdeg", Hasad Bitkisel Üretim. 22,5558.

2. Dwivedi D.H. and Ram R.B. 2008 " chemical composition of bitter apricot kernels from Ladekh" India Acta, 765, 335338

3. Vickery, P.J., Wheeler, J.L. and Mulcahy, C. 1987“" Factors affecting thehydrogen cyanide potential of white clover (Trifolium repens) Aus “. J. Agric. Res., 3 , 1053-105
4. Bruneton J. 1999 . “ Pharmacognosy”, 2nd edn. Intercept, Paris

5. Suchard J.R , Wallace K.L.and Gerkin,R.D.1998. “ Acute cyanide Toxicity caused by apricot kernel ingestion" Ann. Emerg. Med., 32, 742-744

6. Milazzo S, Ernst E, Lejeune S and Schmidt K.2006 " Laetrile treatment for cancer" Cochrane Database Syst Rev . ,2,CD005476.

7. Meijer E and Liikan E .2001. “ Sale over the internet of substances for human consumption which are regarded as harmful in America". OJEC, 44,58-59.

8. Milazzo S., Lejeune S. And Ernst E.2007. "Laetrile for cancer: a systematic review of the clinical evidence", Support Care Cancer, 15, 583-595

9. Chappel, C.1967, Toxicity Studies on Amygdalin, McNaughton Foundation, Montreal, Canada, p.2.

10. Newton, G. W., Schmidt, E. S., Lewis, J. P., Conn, E. and Lawrence, R.1981,"Amygdalin toxicity studies in rats predict chronic cyanide poisoning in humans" west. J. Med. 134,99103.

11. Gomez, E., Burgos, L., Soriano, C. and Marin, J.1998. "Amygdalin content in the seeds of several apricot 
cultivars" , J. Sci. Food Agric. 77,184-186

12. Chandler R.F., Phillipson J.D. and Anderson L.A.1984." Controversial laetrile" Pharm J ,232, 330- 332

13. Qiang L., and Jin-ping, C.2006-09-29. "Water extracting process for amygdalin in almond and its content determination" Food Science , 9:29 .

14. Merkoçi A., Fàbregas E. and Alegret S.1999. "A practical approach to potentiometric biosensors based on consolidated composites: construction and evaluation of a D-amygdalin biosensor "Chem. Educator ,4,137-140

15. Eroberg C.T. and Gonzales S.1978. "Analytical chemistry of amygdalin" Anal. Chem., 50, 317- 322

16. Isozaki T., Matano Y., Yamamoto K., Kosaka N. and Tani T.2001."Quantitative determination of amygdalin epimers by cyclodextrin modified micellar electrokinetic chromatography"

Chromatogr. A, 923, 249-254.

17. Mandenius C.F, Bulow L, Danielsson, B.1983." determination of amygdalinand cynide in industrial food sample using enzymatic methods " Acta Chem.Scand. 37,739-742

18. Badr J.M. and Tawfik M.K.2010." Analytical and pharmacological investigation of amygdalin in prunus armeniaca L. kernels", J. Pharmacy Research ,3, 21342137 Journal of

19. Wasserkrug K. and El-Rassi Z. 1997." High performance liquid phase separation of glycosides 1. Reversed phase chromatography of cyanogenic glycosides with UV and pulsed amperometric detection", J. Liq. Chromatogr. Related Technol, 20, 335-349

20. Wei-Feng L.V., Ding Y.U., and Zheng R.2005. "Isolation and quantitation of amygdalin in apricot kernel and Prunus Tomentosa Thunb. by HPLC with solid phase extraction" J Chromatogr Sci, 43, 383 -387

21. Viorica-Mirela G ,Socaciu C. , Jianu I. ,Florica R. and Florinela F.2006" identification and quantitative evaluation amygdaline from apricot, plum and peach oils and kerneks", Buletin USAMV-CN, 62, 246253

22. Joo W-S. , Jeong J-S.,Kim H., Lee1 Y-M., Lee J-H., and Hong S-P.2006." Prevention of epimerization and quantitative determination of amygdalin in armeniacae semen with schizandrae fructus solution", Arch Pharm Res , 29, 10961101

23. Ngamriabsakul C. and Kommen H.2009. " The preliminary detection of cyanogenic glycosides in Pra (Elateriospermum tapos Blume) by HPLC", Walailak J. Sci . Tech , 6(1), 141-147

24. He L-Y., and Li B-M.1987. "MicroHLPC determination of amygdalin in Semen pruni armeniacae and Semen pruni persicae Biomedical Chromatograph , 2 , 271-273

25. Rauws A.G., L. G. Gramberg L.G. and Olling M.1982." Determination of amygdalin and its major metabolite prunasin in plasma and urine by high pressure liquid chromatography ",Pharmacy WeekblScience, $17,172-175$ 
26. Vogel I.1979. "Textbook of macro and semimacro qualitative inorganic analysis " $5^{\text {th }}$ ed ,Longman Group Ltd ,pp.313

27. Zhao X., Zang W. Zhao X., Wang S., Zheng X. and Zheng J. 2007. "HPLC with column switching coupled to APCIMS for pharmacokinetic study of amygdalin in rabbit plasma" Chromatographia , 65, 149153
28. Femenia A, Rossello C, Mulet A, Canellas J .1995. Chemical Composition of Bitter and Sweet Apricot Kernels. J. Agric. Food Chem. 43,356-361

29. Yildirim1F.A. and Askin M.A 2010. " Variability of amygdaline content in seeds of sweet and bitter apricot cultivars in Turkey" Afric. J. Biotec.” 9, 6522-6524 .

\section{استخلاص وتقدير الأمكدالين في بذور النبات العراقي بالاستخدام المشترك لطريقة التصعيد وكروماتوغرافيا السائل التعالي الادوراء الأينات}

سعاد سلمان محمد" سمية محمد عباس *" زهير عبل الامير خماس "

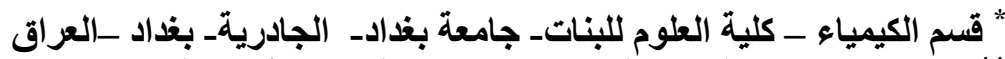

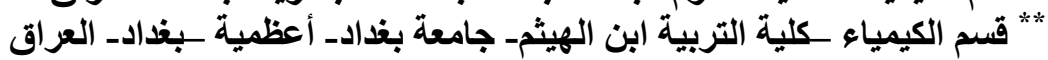

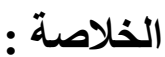

جرى في هذه الدراسة استخلاص وتثخيص وتقدير الأمكالين في بذور النباتات العر اقية باستخدام تدبير التصعيد

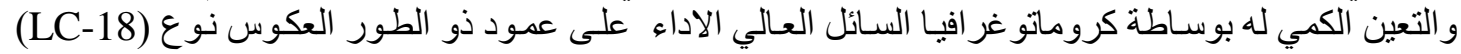

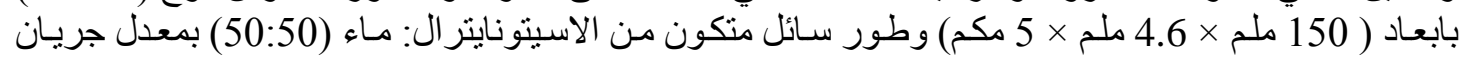

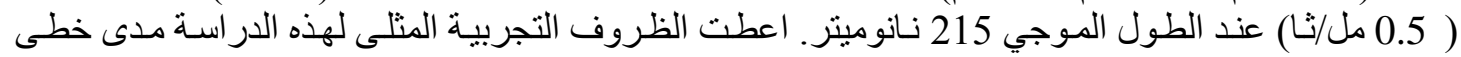

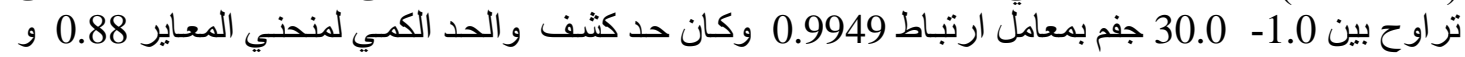

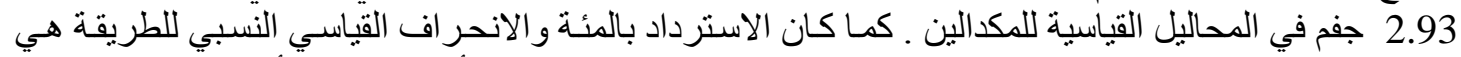

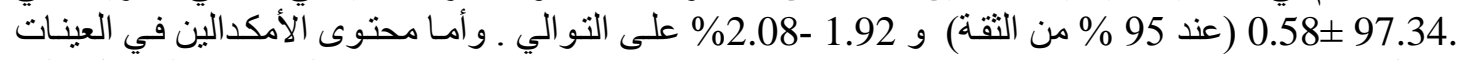

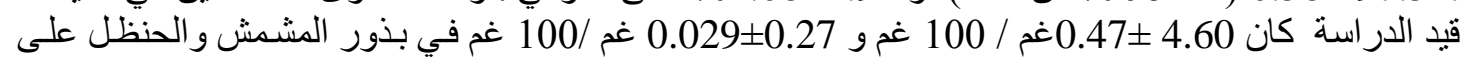

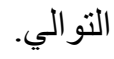

